\title{
Truncus arteriosus communis associated with underdevelopment of the aortic arch
}

\author{
Gaetano Thiene, Francesco Cucchini, and Piero A. Pellegrino \\ From the Departments of Pathology, Cardiology, and Paediatrics, University of Padova Medical School, \\ Padova, Italy
}

\begin{abstract}
Two cases are reported of truncus arteriosus communis arising entirely from the right ventricle and associated with interruption in one case and tubular hypoplasia of the aortic arch in the other. A hatmodynamic hyjothesis of preferential blood flow is proposed to explain this rare association.
\end{abstract}

Truncus arteriosus communis (TAC) is a congenital cardiac anomaly characterized by complete failure of truncoconal septation and partial or total absence of the aortopulmonary septum. Consequently only one great artery leaves the heart above a high ventricular septal defect (VSD) and gives rise to the pulmonary, systemic, and coronary circulation. Collett and Edwards (1949) classified TAC into four types on the basis of the relationship between the pulmonary arteries and the common trunk. Van Praagh and Van Praagh (1965) observed that in TAC there is inverse development of the aortic arch and ductus arteriosus. Thus they classified TAC associated with underdevelopment of the aortic arch and persistent ductus arteriosus as a distinct pathological entity and named it TAC type A4.

Interruption or coarctation of the aortic isthmus is associated with intracardiac lesions which divide the blood flow unequally between the aorta and pulmonary artery at the expense of the aorta (Newcombe et al., 1961; Moller and Edwards, 1965; Sinha et al., 1969; Becker, Becker, and Edwards, 1970; Van Praagh et al., 1971; Hutchins, 1971; Shinebourne and Elseed, 1974). In view of this Van Praagh et al. (1971) believed involution of the aortic arch to be the consequence of a reduced antegrade flow to the ascending aorta during early embryonic development. This hypothesis is supported by the haemodynamic studies carried out on embryos by Rudolph and Heymann (1970), who suggested that blood flow through the aortic arches is or critical importance for their eventual persistence or regression.

The question then arises whether this haemodynamic interpretation applies also to the involution Received 27 Moy 1975. of the aortic isthmus in TAC, where there are no apparent reasons why the cardiac output through the ascending aorta and the pulmonary artery should be unequal. The intracardiac anatomy in the two cases of TAC presented here, one associated with interruption and the other with tubular hypoplasia of the aortic arch, may possibly provide the answer.

\section{Case 1}

\section{Case reports}

A 2-day-old girl was admitted to hospital with mild cyanosis and congestive heart failure. Cardiac catheterization and angiocardiography on the day of admission showed a large high VSD, persistent truncus arteriosus arising from the right ventricle, hypoplasia of the ascending aorta and interrupted aortic arch, and a widely patent ductus arteriosus connecting the truncus with the descending aorta (Fig. 1). The patient died 24 hours after admission.

Post-mortem examination (Fig. 2) showed visceroatrial situs solitus with atrioventricular concordance and apex pointing to the left; normal systemic and pulmonary venous drainage; patent foramen ovale; normal tricuspid valve and enlarged right ventricle; persistent truncus arteriosus, type A4 Van Praagh and Van Praagh (1965), arising entirely from the right ventricle; tricuspid truncal valve and single coronary ostium from the posterior sinus; normal mitral valve; high VSD representing the only outlet for the normal left ventricle; mitrotruncal fibrous continuity and muscular discontinuity between tricuspid and truncal valves; and interrupted aortic arch between the left carotid and the left subclavian arteries (type B of Celoria and Patton, 1959).

\section{Case 2}

A 20-day-old boy was admitted to hospital with signs of severe congestive heart failure and minimal cyanosis. 
Cardiac catheterization and cineangiocardiography showed a high VSD with TAC, tubular hypoplasia of the aortic arch with preductal coarctation, and a widely patent ductus arteriosus (Fig. 3). On the same day as the catheterization the main pulmonary trunk was banded, the patent ductus arteriosus was divided and the coarcta- tion of the aorta resected with end-to-end anastomosis. The patient died four days later.

Post-mortem examination (Fig. 4) showed situs solitus of the viscera and atria with d-loop and cardiac apex on the left; normal systemic and pulmonary venous drainage; atrial septal defect of the fossa ovalis type;
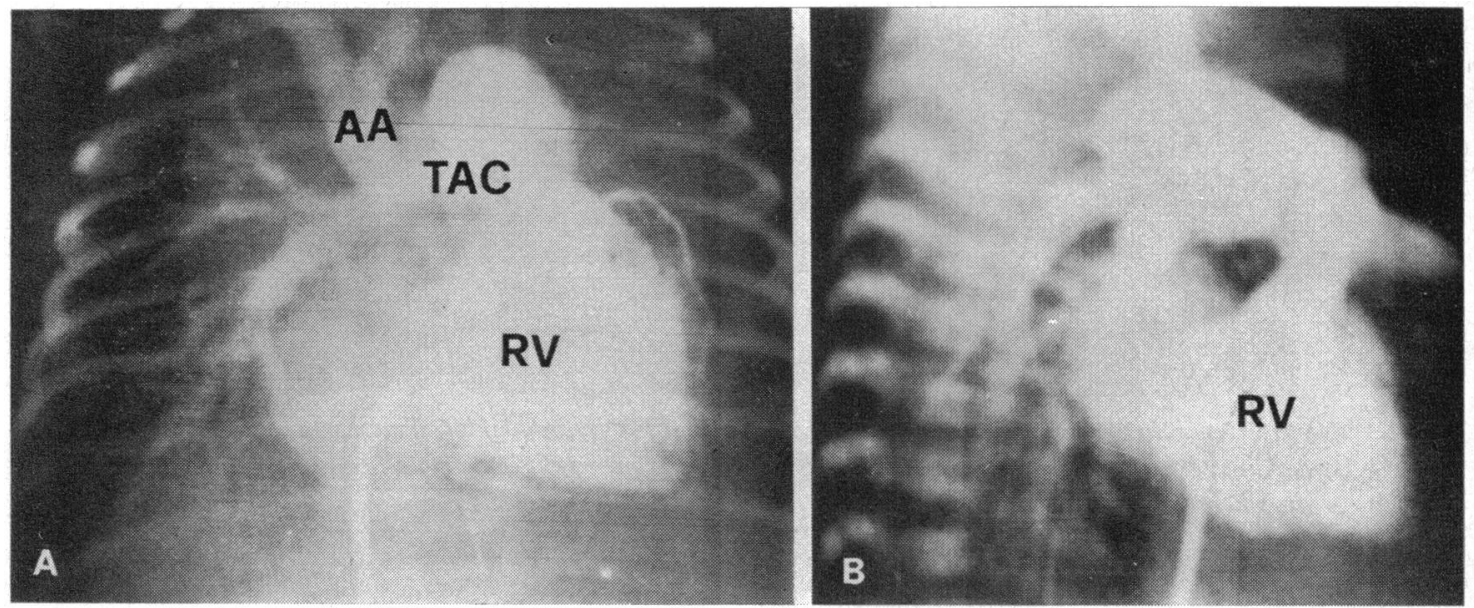

FIG. 1 Case 1. Anteroposterior $(A)$ and lateral (B) views of right ventricular angiogram showing large common trunk (TAC) arising entirely from right ventricle $(R V)$, small ascending aorta $(A A)$, and interrupted aortic arch.
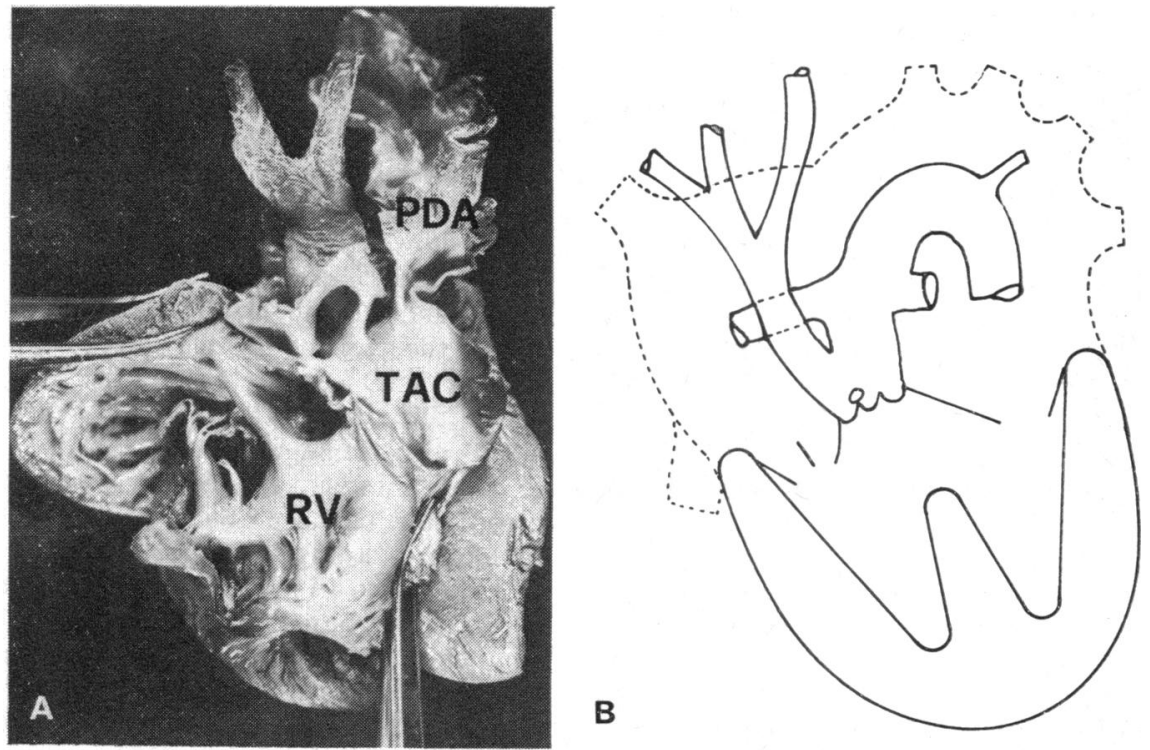

FIG. 2 Case 1. (A) Right ventricle (RV) and common trunk (TAC): note right monoventricular origin of truncus and persistent ductus arteriosus $(P D A)$. (B) Schematic representation of heart and common trunk with interrupted aortic arch, type $B$. 


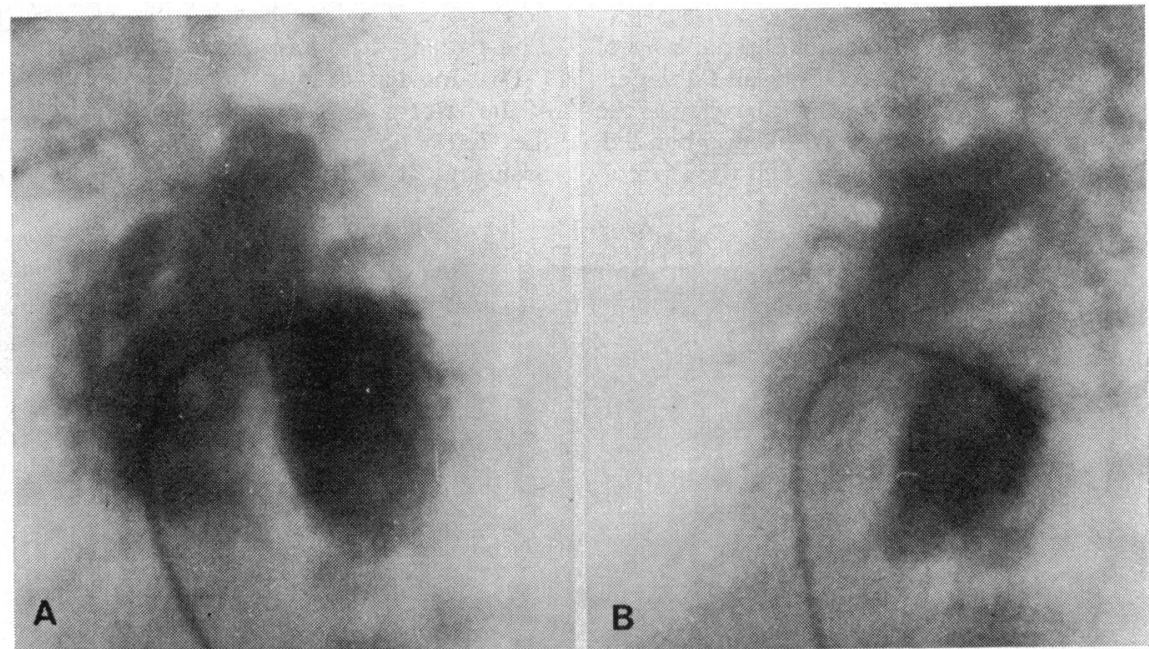

FIG. 3 Case 2. Anteroposterior ( $A)$ and lateral (B) frames of left ventricular cineangiocardiogram showing truncus arteriosus arising from right ventricle and mitrotruncal discontinuity.

normal tricuspid valve and hypertrophy of the right ventricle; monoventricular origin of a type A4 truncus arteriosus communis from the right ventricle; normal mitral valve and hypertrophy of the left ventricle; high subtruncal VSD, representing the only outlet for the left ventricle; conal muscle cuff $5 \mathrm{~mm}$ long separating the tricuspid truncal valve from both atrioventricular valves; single coronary ostium arising from the posterior sinus; banded main pulmonary art 2 ry; divided ductus arteriosus and end-to-end anastomosis between a moderately hypoplastic aortic arch and descending aorta.

\section{Discussion}

In the development of the normal heart both the fourth and sixth left aortic arches persist to connect the ventral aorta to the dorsal aorta. These arches persist because the primitive ventral aorta is totally divided into the ascending aorta and the pulmonary artery by the aortopulmonary septum, so that two distinct ducti are necessary to lead the right and left cardiac outputs into the descending aorta. In TAC, where the aortopulmonary septum is partly or entirely absent (A1 and A2 types of Van Praagh and Van Praagh (1965), respectively), cardiac output is not separated at the level of the ventral aorta. Therefore there are no reasons for both the fourth and sixth left aortic arches to persist. Consequently, in the usual types of TAC (types A1-A2), the ductus arteriousus-that is, the sixth arch-is absent or very small at birth, while the aortic isthmus-that is, the fourth arch-is well developed. More rarely the ductus arteriosus is widely patent as opposed to the aortic isthmus, which is more or less involuted (type A4). Our cases present this last condition and, moreover, both had a monoventricular origin of the common truncus from the right ventricle. A review of the reported cases of TAC type A4 (Tiedemann, 1831; Preisz, 1890; Newcombe et al., 1961; Roberts, Morrow, and Braunwald, 1962; Mehrizi and Morrish, 1962; Van Praagh and Van Praagh, 1965; Morgan, Brinsfield, and Edwards, 1965; Steiner and Finegold, 1965; Moller and Edwards, 1965; Van Praagh et al., 1971) shows that, in those cases where the arterioventricular relationship was described in detail (Newcombe et al., 1961; Steiner and Finegold, 1965), the truncus arose from the right ventricle and the VSD was the only outlet for the left ventricle. The question thus arises whether the right lateral displacement of the truncus plays some role in determining an unequal division of the common blood flow between the ascending aorta and the pulmonary artery. We believe that when the truncus arises from the heart, as in our cases, the predominant blood flow travels from right to left through the left sixth aortic arch and quite possibly predisposes to this kind of aortic isthmal underdevelopment. This differs from Shinebourne and Elseed (1974), who reported that isthmal narrowing is absent in the fetus with a truncus since all the flow reaching the descending aorta will have traversed the isthmus. 
Though in both our cases the truncus arose entirely from the right ventricle the first case showed mitrotruncal fibrous continuity (complete absence of the left parietal conal musculature) while a bilateral parietal conus was present in the second case. After d-looping of the primitive straight heart tube in the early stages of ontogenesis the undivided conotruncus originates entirely from the proximal bulbus cordis (future right ventricle). The studies carried out on human embryos by Goor, Dische,
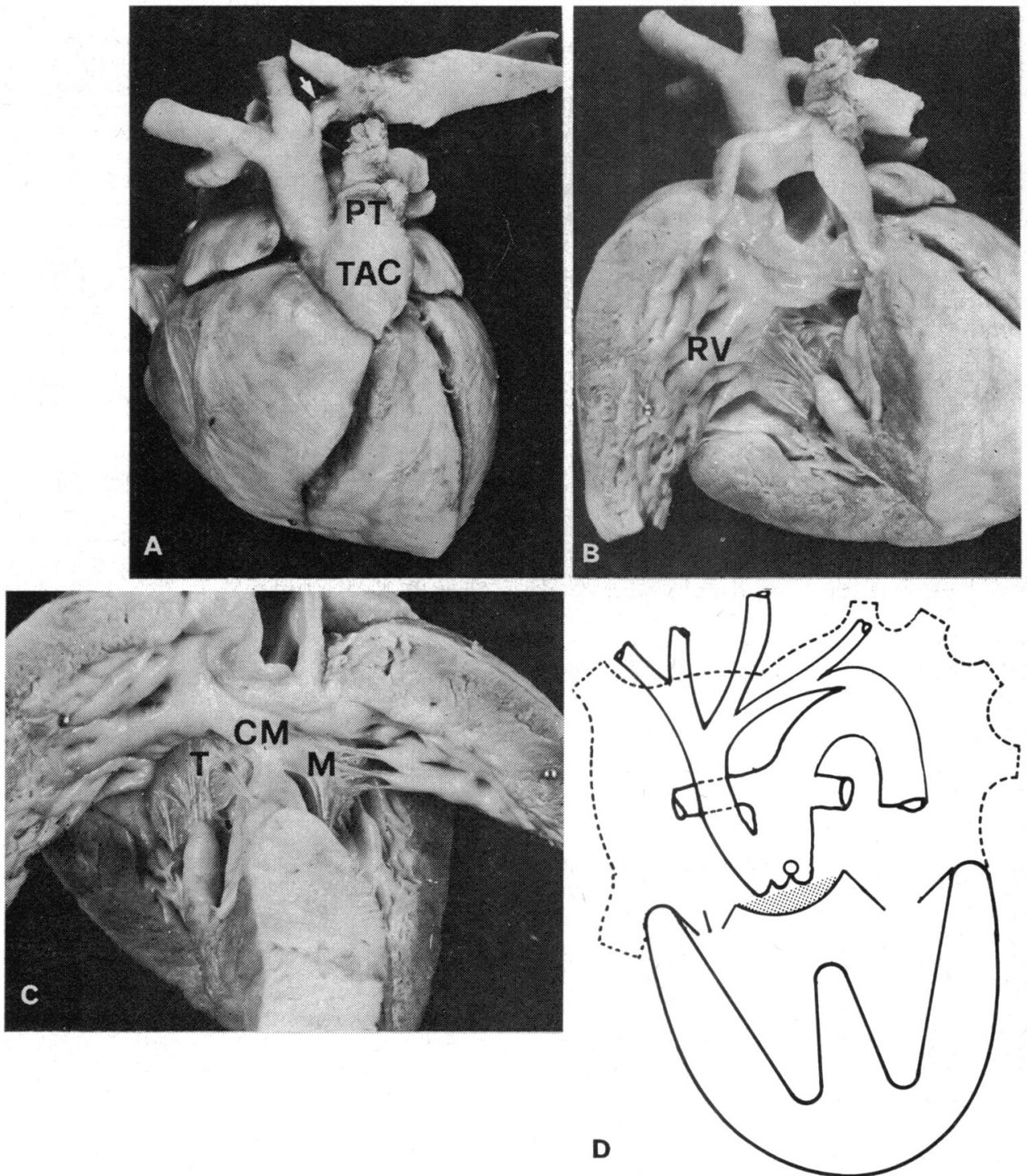

FIG. 4 Case 2. (A) Anteroposterior view of heart. Note common trunk, type A1 (TAC); residual hypoplastic aortic arch (arrow) with signs of surgical end-to-end anastomosis and banded main pulmonary trunk $(P T)$. (B) Interior view of right ventricle $(R V)$ showing right monoventricular origin of common trunk. (C) Interior view of ventricles after excision of high anterior portion of ventricular septum showing large cuff of conal muscle (CM) separating truncal valve from tricuspid (T) and mitral (M) valves. (D) Diagram of anatomy of heart and great arteries. 
and Lillehei (1972) led these authors to postulate that the leftward shift of the conotruncus to align with the left ventricle is independent of the aortic conus absorption-that is, the left posterior wall of the undivided conus. On the other hand, Anderson et al. (1974) believe that this conal absorption is necessary for determining the leftward displacement of the conotruncus. The different anatomical features of our cases, in our opinion, support the conclusions of Goor et al. (1972).

The presence of a bilateral parietal conal myocardium in our second case confirms that TAC is essentially a lack of septation of the outflow tracts of the heart, while the left and right conal free walls may or may not be present. This is in contrast with Van Praagh and Van Praagh's view (1965), who consider the morphogenesis of TAC to be the same as pseudotruncus-that is, an extreme hypoplasia of the conus.

We are indebted to Dr. Richard Van Praagh for his criticism and suggestion.

\section{Addendum}

After this manuscript was submitted, another case of TAC type A4 came to our attention at necropsy, presenting with interrupted aortic arch type $B$ and the truncus arising entirely from the right ventricle despite mitrotruncal fibrous continuity. These anatomical features confirm both our views on the association of underdeveloped aortic arch in TAC with right monoventricular origin of the truncus and on the independence of conus absorption in the transfer of the truncus above the left ventricle.

\section{References}

Anderson, R. H., Wilkinson, J. L., Arnold, R., and Lubkiewicz, K. (1974). Morphogenesis of bulvoventricular malformations. I. Consideration of embryogenesis in the normal heart. British Heart fournal, 36, 242.

Becker, A. E., Becker, M. J., and Edwards, J. E. (1970). Anomalies associated with coarctation of aorta. Particular reference to infancy. Circulation, 41, 1067.

Celoria, G. C., and Patton, R. B. (1959). Congenital absence of the aortic arch. American Heart fournal, 58, 407.
Collett, R. W., and Edwards, J. E. (1949). Persistent truncus arteriosus: a classification according to anatomic types. Surgical Clinics of North America, 29, 1245.

Goor, D. A., Dische, R., and Lillehei, C. W. (1972). The conotruncus. I. Its normal inversion and conus absorption. Circulation, 46, 375.

Hutchins, G. M. (1971). Coarctation of the aorta explained as a branch-point of the ductus arteriosus. American Fournal of Pathology, 63, 203.

Mehrizi, A., and Morrish, H. F. (1962). Interruption of the aortic arch. Bulletin of the fohns Hopkins Hospital, 111, 127.

Moller, J. H., and Edwards, J. E. (1965). Interruption of aortic arch. Anatomic patterns and associated cardiac malformation. American fournal of Roentgenology, 95, 557.

Morgan, A. D., Brinsfield, D., and Edwards, F. K. (1965). Persistent truncus arteriosus. An unusual variant with atresia of the aortic arch. American fournal of Diseases of Children, 109, 74.

Newcombe, C. P., Ongley, P. A., Edwards, J. E., and Wood, E. H. (1961). Clinical, pathologic, and haemodynamic considerations in coarctation of the aorta associated with ventricular septal defect. Circulation, 24, 1356.

Preisz, H. (1890). Beitrage zur Lehre von den angeborenen Herzanomalien. Beitrage zur Pathologischen Anatomie und Physiologie, 7, 245.

Roberts, W. C., Morrow, A. G., and Braunwald, E. (1962). Complete interruption of the aortic arch. Circulation, 26, 39.

Rudolph, A. M., and Heymann, M. A. (1970). Circulatory changes during growth in the fetal lamb. Circulation Research, 26, 288.

Shinebourne, E. A., and Elseed, A. M. (1974). Relation between fetal flow patterns, coarctation of the aorta and pulmonary blood flow. British Heart Fournal, 36, 492.

Sinha, S. N., Kardatzke, M. L., Cole, R. B., Muster, A. J., Wessel, H. U., and Paul, M. H. (1969). Coarctation of the aorta in infancy. Circulation, 40, 385.

Steiner, P., and Finegold, M. J. (1965). Truncus arteriosus with atresia of the aortic arch. Archives of Pathology, 79, 518.

Tiedemann, F. (1831). Abweichende Anordnung der Pulsader-stämme des Herzens. Zeitschrift für Physiologie, 4, 287.

Van Praagh, R., Bernhard, W. F., Rosenthal, A., Parisi, L. F., and Fyler, D. C. (1971). Interrupted aortic arch: surgical treatment. American fournal of Cardiology, 27, 200.

Van Praagh, R., and Van Praagh, S. (1965). The anatomy of common aorticopulmonary trunk (truncus arteriosus communis) and its embryologic implications. A study of 57 necropsy cases. American fournal of Cardiology, 16, 406.

Requests for reprints to Dr. Gaetano Thiene, Istituto di Anatomia Patologica, Via Gabelli 61, Padova, Italy 